\title{
Calculation of motion trajectory and geometric parameters of the trawl during pelagic fishing
}

\author{
Czesław Dymarski, Prof. \\ Jacek Nakielski, Ph. D. \\ Gdansk University of Technology
}

\begin{abstract}
This paper presents a mathematical model of the mass centre motion trajectory of the trawl, its main geometrical parameters, way of solving the model as well as its example results. It could be useful to define optimum parameters of safe, effective and environmentally friendly pelagic fishing.
\end{abstract}

Keywords: Sea fishing, trawl fishing, physical and mathematical model of trawling

\section{INTRODUCTION}

Exploitation of sea life resources undergoes continuous changes which are aimed at fish catch increase on one hand and protection of the resources and ensurance of biological balance to marine ecosystems on the other hand. Various forms of reducing unfavourable consequences of the exploitation are applied a.o. by limiting catch of particular fish kinds as well as by prohibiting application of harmful fishing techniques and preferring environmentally friendly ones. Both worldwide and domestic experience indicate that one of the most important problems is to establish rational technical solutions of exploitation of natural resources especially in the coastal areas and economical zones. In present, greater and greater impact is applied to carrying out selective fishing methods, such as set-nets, drift nets, long lines, drift lines, as well as pelagic and over-seabed trawl fishing. For coastal waters an especially harmful hazard is produced by seabed trawl fishing which results in damaging resident benthonic organisms which play an important role in sea ecosystem. Moreover in Polish coastal zones such kind of fishing produces an additional risk of catching on many obstacles sitting on the sea bed, and in consequence - damage or loss of trawls and caught fishes.

It should be stressed that condition of Polish fishing fleet is very weak today. Majority of Polish ships operating in Baltic Sea waters is in a very bad technical state and use obsolete fishing gear which makes it impossible to carry out highly effective pelagic fishing with controlled position of trawl in sea depth. To compete with fishermen of other EU countries Polish Baltic-Sea fishermen must use modern, economical and ecological ships. To meet the needs relevant research and design projects dealing with modern fishing ships, mainly intended for individual ship owners, have been carried out by teams of Faculty of Ocean Engineering and Ship Technology, Gdańsk University of Technology, for a dozen or so years.

One of the research tasks realized in the frame of the projects is the below presented mathematical model and software for calculation of mass centre motion trajectory and geometric parameters of trawl during pelagic fishing.

\section{ASSUMPTIONS FOR PHYSICAL MODEL OF THE TRAWL}

A fishing cutter together with laid down trawl is presented in a simplified way in Fig. 1.

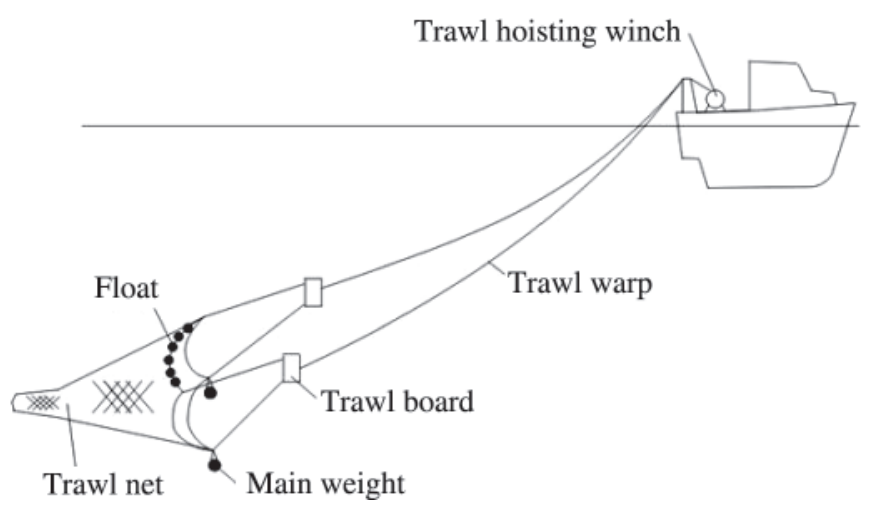

Fig.1. A simplified image of fishing trawl gear

The trawl gear is consisted of trawl warps which are winded around drums of two trawl hoisting winches. The lines go into water through pulley blocks fastened to the aft frame mast. 
Deep in the water they are fixed to the trawl boards by which an appropriate divergence (width) of the trawl net is obtained. From the trawl boards four trawl legs go. Two upper ones are mutually connected through the floatline, two lower ones - through the bottom line. The side legs are connected in pairs through two side lines. To the floatline the floats are connected, due to which an appropriate floatability of the gear is obtained, and the bottom line is loaded, additionally onto the lower trawl legs the main weights are hung. Due to the buoyancy force and applied weights the trawl mouth is shaped in vertical plane. The next element of the trawl gear is its net part consisted of a few conical segments ended with a cylindrical tail into which caught fishes fall.

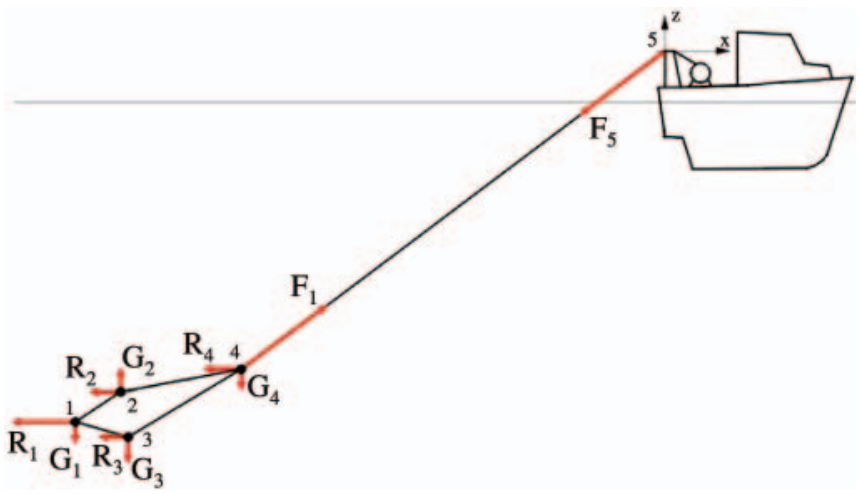

Fig. 2. Simplified model of trawl gear whose particular numbered parts are substituted by their masses concentrated in their gravity centres, namely.

$\mathbf{1}$-trawl net part; $\mathbf{2}$-floats; $\mathbf{3}$-weights: $\mathbf{4}$-trawl boards; 5 -point of line run-out from the ship; $\boldsymbol{G}, \boldsymbol{R}, \boldsymbol{F}$ - gravity, buoyancy, drag and line stretching forces, respectively.

One of the more important problems which occur during pelagic fishing is to appropriately select operational parameters of ship and trawl winches so as to ensure keeping the trawl in operation in a given water depth. So far not many fishing ships have been equipped with instruments to control trawl position hence choice of the above mentioned parameters is mainly based on crew experience. However not always that will do. Many fishermen resign from carrying out such kind of fishing for fear of catching the trawl on various obstacles placed on the sea bottom and loss of the trawl net together with caught fishes. The situation justifies purposefulness of elaboration of a mathematical model and calculation software based on it, which could make it possible to determine trajectory of trawl motion in water during fishing, depending on main operational parameters. Exact calculation of motion trajectories of particular elements of trawl gear immersed in water is a very difficult task not only with a view of possibility of solving the complex and mutually confounded equations but also due to difficulties in defining and describing randomly changeable sea conditions. For this reason such calculations are to be performed under certain, often very far going, simplifying assumptions depending on a given aim and expected accuracy of results to be obtained, resulting from the aim. Below is presented a relatively simple model which makes it possible to determine motion trajectory of trawl gear gravity centre during fishing in waves and at changeable operational parameters of fishing ship or trawl hoisting winch.

To the model the following simplifying assumptions were introduced to describe the above presented trawl gear:

- the trawl gear is symmetrical with respect to ship plane of symmetry, that means that both trawl warps and the part of the gear, connected with them, are of identical geometric, kinematic and dynamic parameters

- the following parts of the gear, namely: trawl net, floats, weights, trawl boards and warps are assumed to be finite material points placed vertically in estimated gravity centers of the parts

the above specified material points have masses and drag areas equivalent to those represented by relevant parts of the gear, and they are connected each to other by means of straight line segments

- motions of the ship, trawl warp and trawl net in waves occur in vertical plane of ship symmetry

trawl warps are assumed to be uniform, perfectly flexible and inextensible strings with taking into account their deflection due gravity and buoyancy forces and hydrodynamic interaction due to their motion in sea water

- the origin of Cartesian coordinate system is located in the point of contact of the trawl warp with ship stern in the place of going the warp down to water.

Schematic diagram of the trawl gear's physical model which satisfies the above specified simplifying assumptions, is shown in Fig. 2 and 3.

\section{MATHEMATICAL DESCRIPTION OF THE ASSUMED MODEL}

To calculate motion trajectory of the trawl gear the equations of component forces applied to its gravity centre can be described as follows:

$$
\begin{aligned}
& R w=\sum_{i=1}^{i=4} R_{i} \quad-\text { total horizontal drag force } \\
& G w=\sum_{i=1}^{i=4} G_{i} \quad-\text { total gravity force in sea water }
\end{aligned}
$$

where:

$$
R_{i}=\frac{\rho \cdot v_{i x}^{2}}{2} \cdot C_{i x} \cdot A_{i x}
$$

$\rho \quad-$ sea water density

$\mathrm{C}_{\mathrm{ix}}, \mathrm{C}_{\mathrm{iz}}-$ drag coefficients of $\mathrm{i}$-th element of the trawl gear in $\mathrm{x}$ - and $\mathrm{z}$ - axis direction, respectively

$\mathrm{A}_{\mathrm{ix}}, \mathrm{A}_{\mathrm{iz}}-$ projected areas of $\mathrm{i}$-th element in $\mathrm{x}-$ and $\mathrm{z}-$ axis direction, respectively

$\mathrm{G}_{\mathrm{i}} \quad$ - weight (buoyancy) of $\mathrm{i}$-th element in sea water

$v_{i x}, v_{i z}-$ velocity of $\mathrm{i}$-th element in $\mathrm{x}-$ and $\mathrm{z}$ - axis direction, respectively:

$$
\begin{aligned}
& v_{\mathrm{ix}}=v_{5 \mathrm{x}}+v_{1} \cdot \cos \alpha_{11} \\
& v_{\mathrm{iz}}=v_{5 \mathrm{z}}+v_{1} \cdot \sin \alpha_{11}
\end{aligned}
$$

$v_{1} \quad$ - velocity of running out "+" (or hauling " “-") the line by the trawl winch

$$
\alpha_{11}=\arctan (\mathrm{Gw} / \mathrm{Rw})
$$

(the angle between the line and $\mathrm{x}$ - axis at its connection with the trawl net)

$v_{5 x} \quad-$ speed of the ship (and the point 5) in $\mathrm{x}$-axis direction, assumed constant

$v_{5 \mathrm{z}} \quad-$ speed of the ship stern (and the point 5) in $\mathrm{z}-$ axis direction, under the assumption that motion of the point 5 due to heave and pitch motions of ship in waves is close to sinusoidal, hence it can described by the equations:

$$
\begin{gathered}
\mathrm{z}_{5}(\mathrm{t})=\mathrm{a}_{5 \mathrm{z}} \cdot \sin (\omega \cdot \mathrm{t}) \\
\mathrm{x}_{5} \approx \mathrm{v}_{5 \mathrm{x}} \cdot \mathrm{t}
\end{gathered}
$$

$\mathrm{a}_{5 \mathrm{z}}-$ displacement amplitude of the point 5 in $\mathrm{z}-$ axis direction 


$$
\omega=2 \cdot \pi / \mathrm{T}
$$

where:

$\begin{array}{ll}\mathrm{T} & - \text { ship pitch period } \\ \mathrm{t} & - \text { time. }\end{array}$

Calculation of shape of the trawl warp in vertical plane was performed by using the numerical method in accordance with the model presented in Fig. 3.
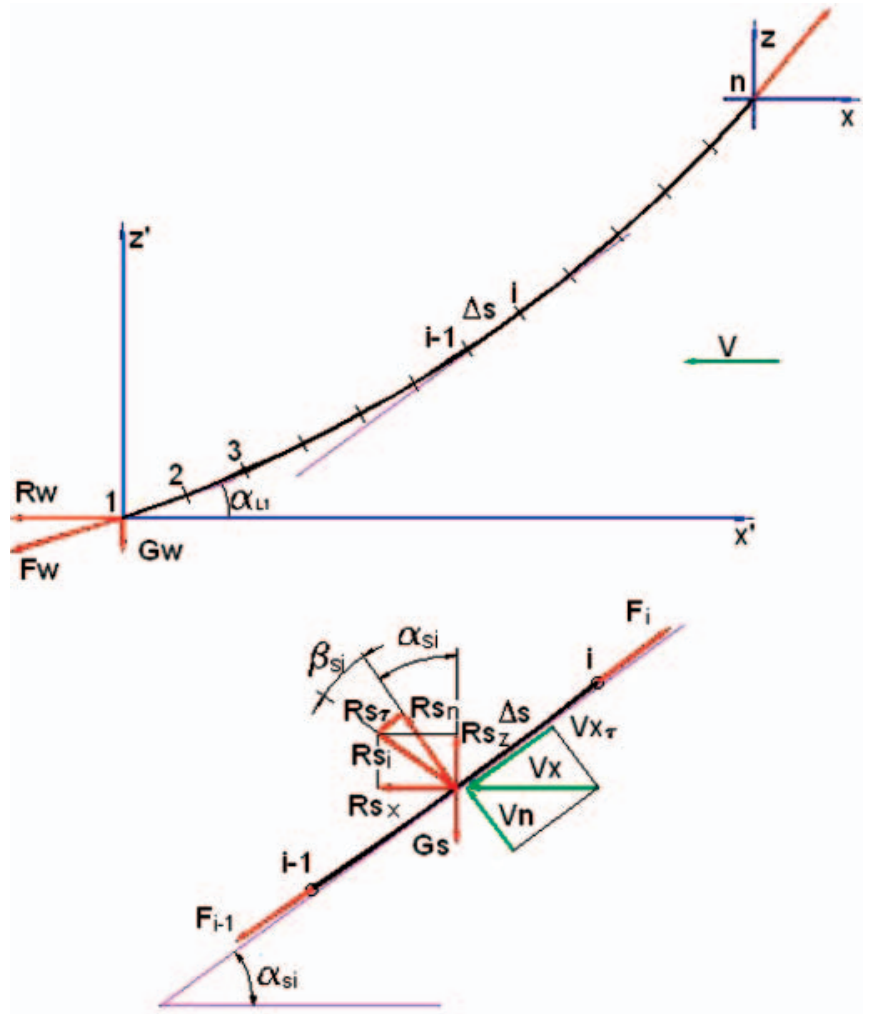

Fig. 3. Simplified model of shape of the trawl warp (line), taken to numerical calculations

The force in the end of the trawl warp at the point of its connection with the trawl body is equal to:

$$
\mathrm{Fw}=\mathrm{F}_{1.1}=\sqrt{\mathrm{Rw}^{2}+\mathrm{Gw}^{2}}
$$

and, in an arbitrary point of the line it can be calculated from the relation:

$$
\mathrm{F}_{\mathrm{li}_{\mathrm{i}}}=\mathrm{F}_{\mathrm{li}_{\mathrm{i}-1}}+\Delta \mathrm{F}_{\mathrm{li}_{\mathrm{i}}}
$$

where:

$$
\begin{gathered}
\mathrm{F}_{\mathrm{li}_{\mathrm{i}-1}}=\mathrm{F}_{\mathrm{w}}+\sum_{\mathrm{k}=2}^{\mathrm{k}=\mathrm{i}} \Delta \mathrm{F}_{\mathrm{lk}} \\
\Delta \mathrm{F}_{\mathrm{i}}=\sqrt{\mathrm{Rs}_{\mathrm{Xi}}^{2}+\left(\mathrm{Gs}-\mathrm{Rs}_{\mathrm{Zi}}\right)^{2}}
\end{gathered}
$$

Gs - weight of the calculated segment of the line in sea water

$$
\begin{aligned}
& \mathrm{Rs}_{\mathrm{Xi}}=\mathrm{Rs}_{\mathrm{i}} \cdot \sin ^{2}\left(\alpha_{\mathrm{si}}+\beta_{\mathrm{i}}\right) \\
& \mathrm{Rs}_{\mathrm{Zi}}=\mathrm{Rs}_{\mathrm{i}} \cdot \cos ^{2}\left(\alpha_{\mathrm{si}}+\beta_{\mathrm{i}}\right)
\end{aligned}
$$

$\alpha_{\mathrm{si}} \quad-$ average slope angle of the calculated segment of the line, calculated from the following interpolation:

$$
\alpha_{\mathrm{si}}=1.5 \cdot \alpha_{\mathrm{i}-1}-0.5 \cdot \alpha_{\mathrm{i}-2}
$$

$\alpha_{i-1,}, \alpha_{i-2}-\begin{aligned} & \text { slope angles of the line in the points } i-1 \text { and } i-2 \text {, } \\ & \text { respectively }\end{aligned}$

$$
\begin{gathered}
\beta_{11}=\arctan \left(\mathrm{Rs}_{\mathrm{\tau i}} / \mathrm{Rs}_{\mathrm{ni}}\right) \\
\mathrm{Rs}_{\mathrm{i}}=\sqrt{\mathrm{Rs}_{\mathrm{ni}}{ }^{2}+\mathrm{Rs}_{\tau \mathrm{i}}{ }^{2}}
\end{gathered}
$$

(resultant drag force of the calculated segment of the line)

$$
\mathrm{Rs}_{\mathrm{ni}}=0.5 \cdot \mathrm{Cn} \cdot \rho \cdot \mathrm{v}_{\mathrm{x}}^{2} \cdot \mathrm{d} \cdot \Delta \mathrm{S} \cdot \sin ^{2} \alpha_{\mathrm{si}}
$$

(drag force of the calculated segment of the line in the direction perpendicular to it)

$$
\mathrm{Rs}_{\mathrm{ti}}=0.5 \cdot \mathrm{C} \tau \cdot \rho \cdot \mathrm{v}_{\mathrm{x}}^{2} \cdot \mathrm{d} \cdot \Delta \mathrm{S} \cdot \cos ^{2} \alpha_{\mathrm{si}}
$$

(drag force of the calculated segment of the line in the direction parallel to it)

where:

$\mathrm{Cn}$ - drag coefficient of the line in the direction perpendicular to it

$\mathrm{C} \tau-$ drag coefficient of the line in the direction parallel to it

d $\quad-$ diameter of the line

$\Delta \mathrm{S} \quad-$ length of the elementary (calculated) segment of the line.

Coordinates of an arbitrary point $i$ of the trawl warp relative to the point of its connection with the trawl body were determined from the following relations:

$$
\begin{gathered}
x_{i}^{I}=x_{i-1}^{I}+\Delta S \cdot \cos \alpha_{S i} \\
z_{i}^{I}=z_{i-1}^{I}+\Delta S \cdot \sin \alpha_{S i}
\end{gathered}
$$

and the slope angle of the line - from the interpolation formula:

$$
\alpha_{\mathrm{li}}=\alpha_{\mathrm{li}-1}+2 \cdot\left(\alpha_{\mathrm{Si}-1}-\alpha_{\mathrm{li}-1}\right)=2 \cdot \alpha_{\mathrm{Si}-1}-\alpha_{\mathrm{li}-1}
$$

Any motion of the point 5 in $\mathrm{z}$ - axis direction will produce definite changes in loads in the line and displacements of the gravity centre of the trawl gear. The equation of forces acting on the trawl gear in $\mathrm{z}$ - axis direction takes the following form:

$$
m \frac{d^{2} z}{d t^{2}}=m g-F_{z}-\frac{\rho}{2}\left(\frac{d z}{d t}\right)^{2} \cdot \sum_{i=1}^{i=4}\left(C_{i z} \cdot A_{i z}\right)
$$

where:

$$
\mathrm{m}=\sum_{\mathrm{i}=1}^{\mathrm{i}=4} \mathrm{~m}_{\mathrm{i}}
$$

(total mass of the trawl gear elements in sea water)

$$
\mathrm{z}=-\mathrm{z}_{\mathrm{n}}^{\mathrm{I}}
$$

(vertical coordinate of the trawl gear gravity centre, relative to the point 5)

$$
1=1_{0}+v_{1} \cdot t
$$

(current length of the run-out trawl warp)

$$
\mathrm{F}_{\mathrm{z}}=\mathrm{R} \cdot \operatorname{tg} \alpha_{11}
$$

(vertical force component in the line, acting on the trawl gear)

To solve the differential equations Runge-Kutta method was used. At first the following substitution was introduced:

$$
\mathrm{y}=\frac{\mathrm{dz}}{\mathrm{dt}}
$$

On substitution of Eq. (29) to Eq. (24) and appropriate transformations the following was obtained: 


$$
\begin{aligned}
\frac{d y}{d t}=g & -\frac{\rho}{2 \cdot m} \cdot \sum_{i=1}^{i=4}\left(C_{i x} \cdot A_{i x} \cdot v_{i x}^{2}\right) \cdot \operatorname{tg} \alpha_{11}(t)+ \\
& -\frac{\rho}{2 \cdot m}\left(\frac{d z}{d t}\right)^{2} \cdot \sum_{i=1}^{i=4}\left(C_{i z} \cdot A_{i z}\right)
\end{aligned}
$$

The calculation process was realized by applying a constant time step and assuming the results of the preceding step to be initial value for the successive calculation step.

To calculate geometric parameters of the trawl gear in steady operational conditions the above given mathematical description was supplemented by the following additional relations to which the notations complying with Fig. 4 were introduced:

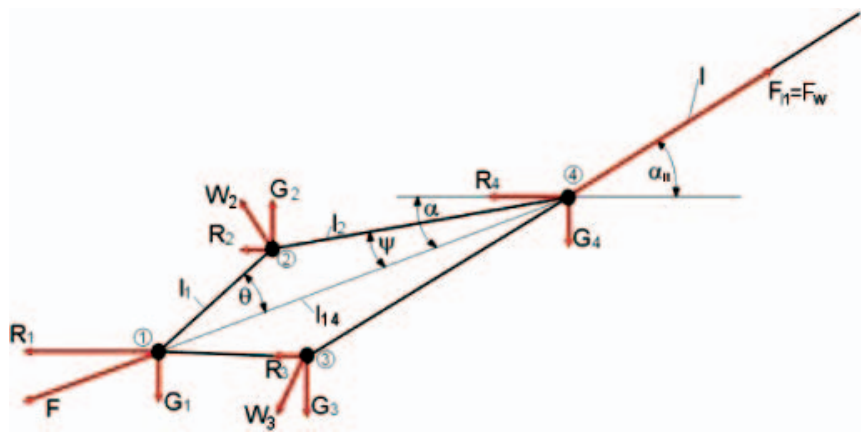

Fig. 4. Simplified model of the trawl gear, with indicated load vectors and main geometric parameters

$$
\theta=\arctan \left(\frac{2 \cdot\left(\mathrm{G}_{2} \cdot \cos \alpha+\mathrm{R}_{2} \cdot \sin \alpha\right)}{\sqrt{\mathrm{R}_{1}^{2}+\mathrm{G}_{1}^{2}}}\right)
$$

In the first calculation step:

$$
\begin{gathered}
\alpha=\alpha_{1} \\
\psi=\arcsin \left(\frac{l_{1}}{l_{2}} \cdot \sin \theta\right)
\end{gathered}
$$

If the above mentioned angles and the line length is known it is possible to determine coordinates of gravity centers of particular parts of the trawl gear, namely:

$$
\begin{gathered}
\mathrm{x}_{4}=-\mathrm{x}_{\mathrm{n}}^{\mathrm{I}} \\
\mathrm{z}_{4}=-\mathrm{z}_{\mathrm{n}}^{\mathrm{I}} \\
\mathrm{x}_{3}=\mathrm{x}_{4}-1_{2} \cdot \cos (\alpha+\psi) \\
\mathrm{z}_{3}=\mathrm{z}_{4}-1_{2} \cdot \sin (\alpha+\psi) \\
\mathrm{x}_{2}=\mathrm{x}_{4}-1_{2} \cdot \cos (\alpha-\psi) \\
\mathrm{z}_{2}=\mathrm{z}_{4}-1_{2} \cdot \sin (\alpha-\psi) \\
\mathrm{x}_{1}=\mathrm{x}_{4}-1_{1} \cdot \cos \theta-1_{2} \cdot \cos \psi \\
\mathrm{z}_{1}=\mathrm{z}_{4}-1_{1} \cdot \sin \theta-1_{2} \cdot \sin \psi
\end{gathered}
$$

Then, for the so determined geometry of the gear the moment in the point 4 , which tends to rotate the gear with respect to the point, is calculated.

$$
\begin{gathered}
\mathrm{M}_{4}=\mathrm{G}_{1} \cdot 1_{14} \cdot \cos \alpha+\mathrm{G}_{2} \cdot 1_{2} \cdot \cos (\alpha-\psi)+ \\
+\mathrm{G}_{3} \cdot 1_{4} \cdot \cos (\alpha+\psi)-\mathrm{R}_{1} \cdot 1_{14} \cdot \sin \alpha+ \\
-\mathrm{R}_{2} \cdot 1_{2} \cdot \sin (\alpha-\psi)-\mathrm{R}_{3} \cdot 1_{4} \cdot \cos (\alpha+\psi) \\
1_{14}=1_{1} \cdot \cos \theta+1_{2} \cdot \cos \psi
\end{gathered}
$$

In the case when a calculated value of the moment is greater than an assumed accuracy, for the next calculation step a little greater or smaller value of the angle $\alpha$ is taken, depending on sign of the moment. When a sufficiently accurate result is achieved the coordinates of the points 1 through 4 and then the moment relative to the point 5 are calculated for the new geometry of the trawl gear.

$$
\begin{gathered}
M_{5}=G_{1} \cdot\left(l_{1-4} \cdot \cos \alpha+x_{4}\right)+G_{2} \cdot\left[l_{2} \cdot \cos (\alpha-\psi)+x_{4}\right]+ \\
+G_{3} \cdot\left[l_{4} \cdot \cos (\alpha+\psi)+x_{4}\right]+G_{4} \cdot x_{4}+ \\
-R_{1} \cdot\left(l_{1-4} \cdot \sin \alpha+z_{4}\right)-R_{2} \cdot\left[l_{2} \cdot \sin (\alpha-\psi)+z_{4}\right]+ \\
-R_{3} \cdot\left[1_{4} \cdot \cos (\alpha+\psi)+z_{4}\right]-R_{4} \cdot z_{4}
\end{gathered}
$$

Like before, the angle $\alpha_{11}$ will be corrected depending on value and sign of the moment until its values in successive iteration steps are sufficiently accurate.

The computer software in question was written in Fortran programming language to make it possible to carry out calculations in various working conditions.

\section{RESULTS OF NUMERICAL SIMULATIONS}

Below are presented example results of the calculations of the trawl gravity centre motion trajectory, performed for the following operational conditions: $v_{x}=1.5 \mathrm{~m} / \mathrm{s} ; 1=300 \mathrm{~m}$; $\mathrm{a}_{0}=0.5 \mathrm{~m} ; \mathrm{T}=7 \mathrm{~s} ; \mathrm{C}_{\mathrm{n}}=1.2 ; \mathrm{C}_{\tau}=0.02 ; \mathrm{d}=0,01 \mathrm{~m}$ and three values of rope velocity: $v_{1}=0 ; 0.06$; and $-0.06 \mathrm{~m} / \mathrm{s}$.

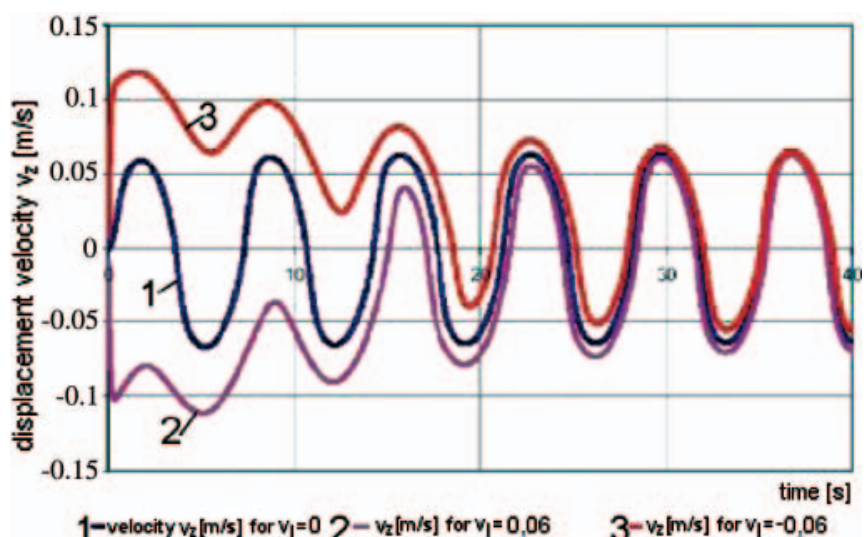

Diag. 1. Diagram of trawl displacement velocity for the parameters: $v_{s}=1.5 \mathrm{~m} / \mathrm{s} ; l=300 \mathrm{~m} ; a_{0}=0.5 \mathrm{~m}$ and $T=7 \mathrm{~s}$.

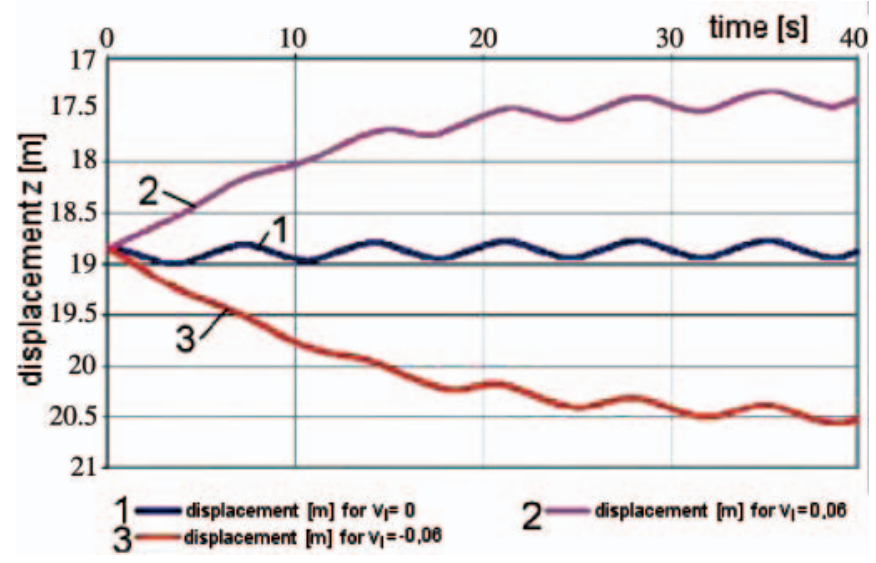

Diag. 2. Diagram of trawl displacement for the parameters: $v_{s}=1.5 \mathrm{~m} / \mathrm{s} ; l=300 \mathrm{~m} ; a_{0}=0.5 \mathrm{~m}$ and $T=7 \mathrm{~s}$.

The oscillations of the trawl gear gravity centre of for $300 \mathrm{~m}$ length of the laid-down line and the trawling speed of $1.5 \mathrm{~m} / \mathrm{s}$, amount to $0.226 \mathrm{~m}$ and along with the increasing of trawling speed 
they maintain on similar level. And, the displacement velocity of the gravity centre amounts to $v_{z}= \pm 0.06 \mathrm{~m} / \mathrm{s}$ on average. In the case of decreasing the initial length of the laid-down line the mean value of oscillation amplitude increased up to $0.289 \mathrm{~m}$ and the displacement velocity was equal to almost $\pm 0.09 \mathrm{~m} / \mathrm{s}$.

It should be also observed that for $300 \mathrm{~m}$ length of the laid-down line, for the first several seconds (one period) after switching the winch on line hauling mode, the ,flattening" of the displacement characteristics occurs at simultaneous deviation of its mean value. The emerging of the trawl occurs relatively fast at simultaneous insignificant increasing the amplitude of oscillation, and an increase of its draught with accompanying decrease of the oscillation amplitude takes place during laying down the line. The trawl velocity $\mathrm{v}_{\mathrm{z}}$, after starting the winch and transient disturbances resulting from that, tends to be close to the initial velocity except that, as expected, oscillation amplitude value increases in the case of hauling the line and decreases during laying down the line. The increasing of trawling speed or decreasing of length of the laid-down line does not cause any distinct intensification of the above mentioned phenomena.

Below in Tab. 1. and the diagrams are presented example results of the numerical calculations performed for two values of the laid-down line length $1=300 \mathrm{~m}$ and $150 \mathrm{~m}$ as well as five values of the ship speed $v_{s}=1 ; 1.25 ; 1.5 ; 1.75$ and $2 \mathrm{~m} / \mathrm{s}$.

Tab. 1. Results of the simulations

\begin{tabular}{|c|c|c|c|c|c|}
\hline $\begin{array}{c}\mathbf{v}_{\mathbf{x}} \\
{[\mathbf{m} / \mathbf{s}]}\end{array}$ & $\begin{array}{c}\mathbf{I} \\
{[\mathbf{m}]}\end{array}$ & $\begin{array}{c}\boldsymbol{\alpha}_{1} \\
{\left[{ }^{\circ}\right]}\end{array}$ & $\begin{array}{c}\boldsymbol{\alpha} \\
{\left[{ }^{\circ}\right]}\end{array}$ & $\begin{array}{c}\boldsymbol{\theta} \\
{\left[{ }^{\circ}\right]}\end{array}$ & $\begin{array}{c}\boldsymbol{\psi} \\
{\left[{ }^{\circ}\right]}\end{array}$ \\
\hline 1 & 300 & 6.451 & 6.138 & 7.834 & 3.168 \\
\hline 1 & 150 & 6.451 & 5.958 & 7.834 & 3.168 \\
\hline 1.25 & 300 & 4.139 & 3.941 & 5.064 & 2.051 \\
\hline 1.25 & 150 & 4.139 & 3.827 & 5.064 & 2.051 \\
\hline 1.5 & 300 & 2.877 & 2.740 & 3.530 & 1.430 \\
\hline 1.5 & 150 & 2.877 & 2.661 & 3.530 & 1.430 \\
\hline 1.75 & 300 & 2.114 & 2.014 & 3.597 & 1.053 \\
\hline 1.75 & 150 & 2.114 & 1.956 & 3.597 & 1.053 \\
\hline 2 & 300 & 1.619 & 1.543 & 1.990 & 0.807 \\
\hline 2 & 150 & 1.619 & 1.498 & 1.990 & 0.807 \\
\hline
\end{tabular}

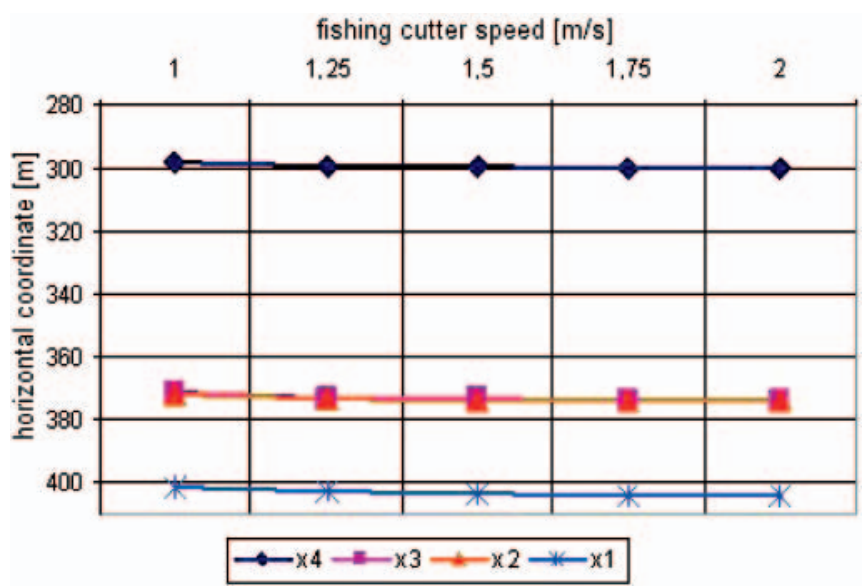

Diag. 3. Calculated values of the horizontal coordinate $x$ of the points $1 \div 4$ for $l=300 \mathrm{~m}$ and $v_{s}=1 \div 2 \mathrm{~m} / \mathrm{s}$.

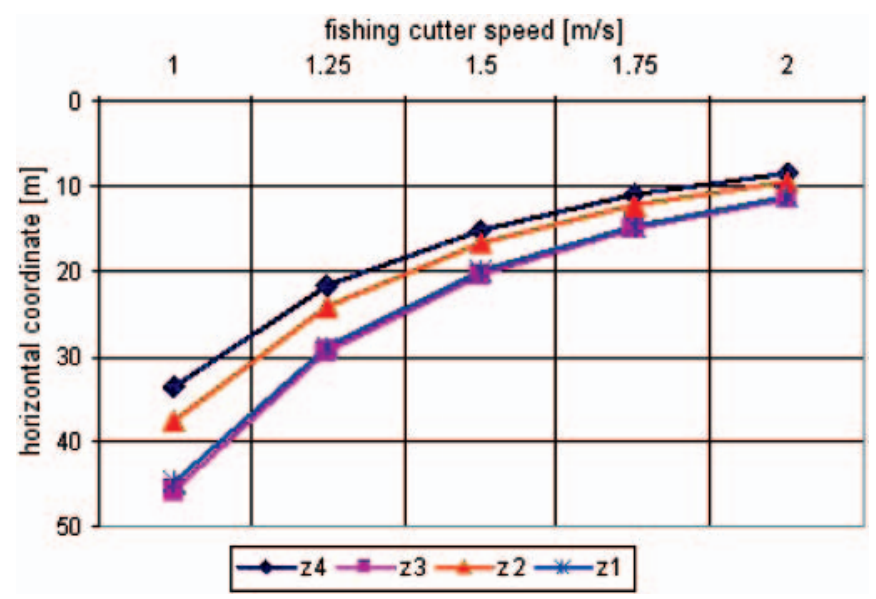

Diag. 4. Calculated values of the vertical coordinate z of the points $1 \div 4$ for $l=300 \mathrm{~m}$ and $v_{s}=1 \div 2 \mathrm{~m} / \mathrm{s}$.
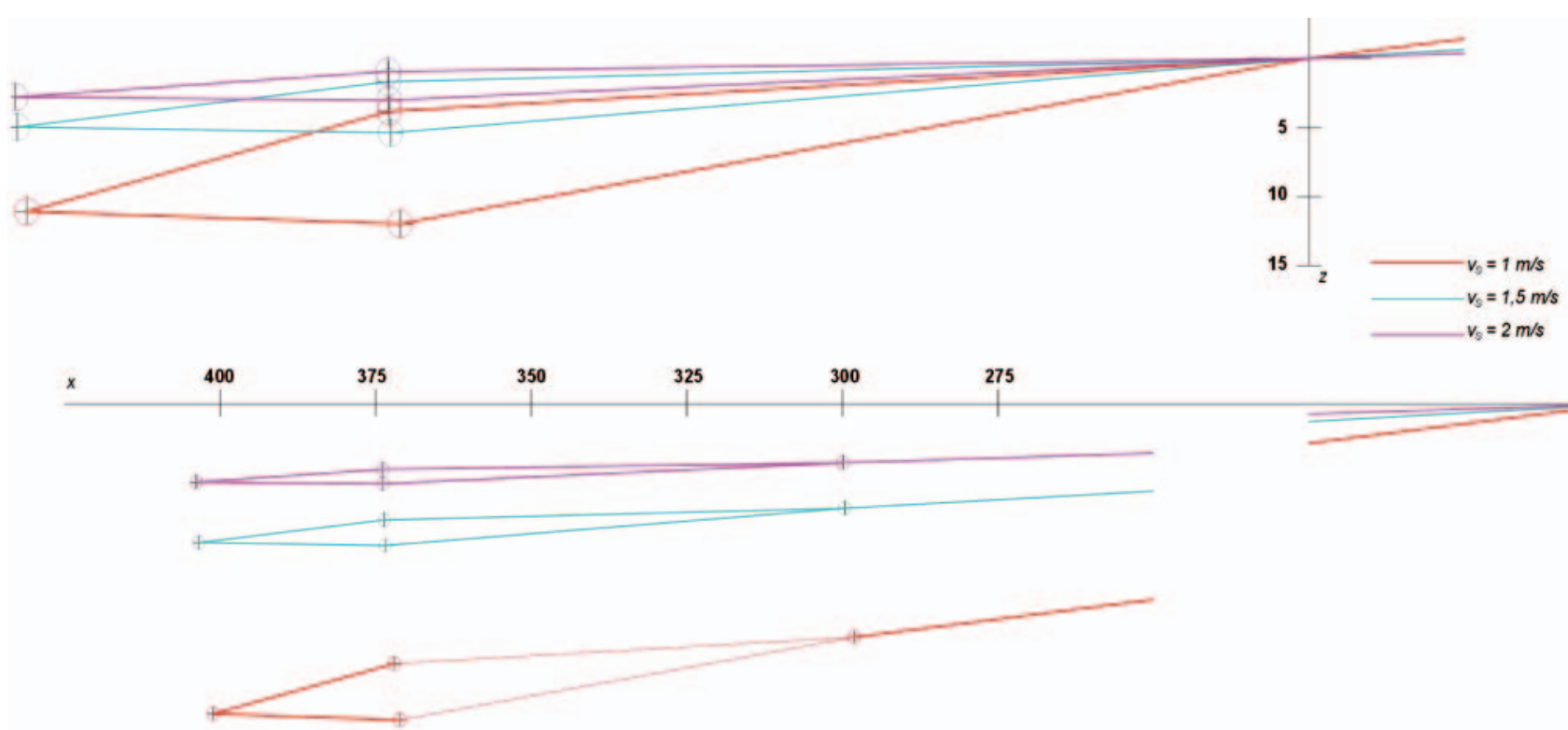

Diag. 5. Simplified shape of the trawl gear in function of its speed, for the laid-down line length $l=300 \mathrm{~m}$ 


\section{FINAL COMMENTS}

- The elaborated, relatively simple model of the trawl gear as well as calculation software make it possible to determine the gravity centre motion trajectory of the trawl gear immersed in sea water, depending on the main operational parameters such as: ship speed, speed of hauling or laying-down the line by trawl winches, length of the laid-down line as well as amplitude and period of ship stern displacements.

- The model makes it possible also to determine position of the trawl gear main parts as well as divergence (width) of the trawl mouth for definite values of the main design and operational parameters of the gear. This is as much important that the so obtained data can be used during performance of fishing. By appropriate selecting the operational parameters a current position of the trawl and its mouth width can be adjusted to a localized fish shoal, moreover any danger of catching the trawl on underwater obstacles can be avoided this way.

\section{BIBLIOGRAPHY}

1. Bessomneau J.S., Marichel D.: Study of the dynamics of submerged supple nets (application to trawls). Ocean Engineering, 25, 1998

2. Bielański J.: The analysis of the system towing rope with long underwater object. Hydroacoustics, 9, Gdańsk 2006

3. Brewek D., Eayrs S., Mounsey R., You-Gan W.: Assessment of an environmentally friendly, semipelagic fish trawl. Fisheries Research, 1996
4. Chun-Woo L., Ju-Hee L., Bong Jin Ch., Hyun-Young K.: Physical modeling for underwater flexible systems dynamic simulation. Ocean Engineering. 32, 2005

5. Erinfolami L. A.: Investigations of interaction between ship power system and fishing trawl gear (in Polish). Doctor thesis, Gdańsk University of Technology, Gdańsk, 2000

6. Huang S.: Dynamic analysis of three-dimensional marine cables. Ocean Engineering, 21, 1994

7. Moderhak W.: A calculation method of total hydrodynamic drag of the pelagic trawl net (in Polish). Doctor thesis, Gdańsk University of Technology, Gdańsk 1991

8. Piechna J. R.: Programming in the language Fortran 90 and 95 (in Polish). Publishing House of Warsaw University of Technology (Oficyna Wydawnicza Politechniki Warszawskiej), Warszawa 2000

9. Pogański Z.: Prospects for Baltic Sea fishery (in Polish). Nautologia, 2, Gdynia 1998

10.Wu J., Chwang A. T.: A hydrodynamic model of a two-part underwater towed system. Ocean Engineering, 27, 2000

11.Wu J., Chwang A. T.: Experimental investigation on a two-part underwater towed system. Ocean Engineering, 28, 2001

\section{CONTACT WITH THE AUTHORS}

Czesław Dymarski, Prof. Jacek Nakielski, Ph. D.

Faculty of Ocean Engineering and Ship Technology,

Gdańsk University of Technology Narutowicza 11/12

80-952 Gdańsk, POLAND

e-mail: cpdymars@pg.gda.pl 